\section{Review}

\section{"Corresponding author}

Aissi Adel, DVM, Dip MSc, Dip Dsc, HDR

Associate Professor

Head of Surgery and Veterinary Imaging

Services, Batna University

1 Batna 05000, Algeria

Tel. 0668070105

E-mail: adelaissi050@gmail.com

Volume 2 : Issue 3

Article Ref. \#: 1000VMOJ2120

\section{Article History}

Received: August 16 $6^{\text {th }}, 2017$

Accepted: September $28^{\text {th }}, 2017$

Published: September 29 $9^{\text {th }}, 2017$

\section{Citation}

Khadidja M, Adel A. Canine prostatic disorders. Vet Med Open J. 2017; 2(3): 83-90. doi: 10.17140/VMOJ-2-120

\section{Copyright}

(C)2017 Adel A. This is an open access article distributed under the Creative Commons Attribution 4.0 International License (CC BY 4.0), which permits unrestricted use, distribution, and reproduction in any medium, provided the original work is properly cited.

\title{
Canine Prostatic Disorders
}

Madani Khadidja, DVM Doctoral Student' ${ }^{1}$ Aissi Adel, DVM, DipMSc, Dip Dsc, HDR ${ }^{2,3^{*}}$

${ }^{1}$ Veterinary Institute, University of Tiaret, 14000 Tiaret, Algeria

${ }^{2}$ Surgery and Veterinary Imaging Services, Veterinary Institute, Batna University, 1 Batna 05000, Algeria

${ }^{3} \mathrm{Head}$ of Surgery and Veterinary Imaging, Veterinary Institute, Batna University, 1 Batna 05000, Algeria

\section{ABSTRACT}

Background: The prostatic syndrome in male dogs shows a varying range of clinical implications. Prostatic syndrome in dogs is characterized by non-pathognomonic clinical symptoms affecting urinary, digestive, and locomotory functions. The nature of prostatic disease in dogs cannot be diagnosed without further clinical examination. Radiological examination, ultrasound examination and analysis of the prostatic fluid makes it possible to ascertain a reliable and accurate diagnosis.

Objectives: This review presents information on the canine prostatic pathology and the application of different methods for its treatment.

Results: The prostatic syndrome in male dogs is associated with varied medical conditions. Some conditions, benign forms like prostate hyperplasia (BPH), are quite common. More serious ailments, such as cysts, abscesses, and neoplasms are rare in occurrence. Prostatic syndrome in dogs are marked by clinical symptoms resulting in dysfunction of the urinary, digestive, and the locomotory system. A reliable mode of diagnosis for prostatic conditions in dogs is mediated by undertaking radiological examination, ultrasound examination and analysis of the prostatic fluid.

Conclusion: Prostatic disorders in dogs present a uniformity of medical symptoms affecting the urinary, digestive, locomotory functions, with a heterogeneity of lesions in the form of hyperplasia, prostatitis and tumor formation which demands rigorous differential diagnosis for the establishment of effective medical or surgical treatment.

KEY WORDS: Dog; Prostate; Infection; Tumor; Radiology; Ultrasound.

\section{INTRODUCTION}

The prostate is a vital male sexual accessory gland. Its main role is the secretion of prostatic fluid which constitutes the major part of the volume of ejaculated sperm. The development of the prostate is regulated by testosterone, the hormone secreted by the testicles and adrenal glands. The prostate shows an increasing sensitivity to this hormone.

Under the hormonal influence, the prostate undergoes physiological and sometimes pathological changes. In the elderly dogs, the prostate is the affected site in various benign medical conditions such as prostatic hyperplasia as well as cysts, abscesses and rarely prostatic adenocarcinomas. It is therefore interesting to examine these prostatic conditions, to perform a better clinical diagnosis and offer the best treatment strategy.

In this paper, the anatomy and physiology of the prostate gland has been recalled. Next, the different prostate pathologies have been discussed. The last few sections emphasize on the clinical approach to treat medical suspicions affecting the prostatic pathology.

\section{MORPHOLOGY}

The prostate is an odd and median organ, ovoid or spherical, bilobed and grayish in color, sur- 
rounded by a fibromuscular capsule. At the cut, the prostate is formed of numerous tubuloalveolar glands. The two prostatic lobes are separated by a median groove, dorsally shallow and broad, and ventrally fine and narrow. The normal prostate is smooth, firm and elastic. ${ }^{1}$

\section{Anatomy}

The prostate is the primary male sexual accessory gland. It is located in the pelvis where it rests on the cranial border of the pubis in young animals. ${ }^{2,3}$ In animals, the prostate is exclusively intra-pelvic until sexual maturity, then increases in volume with age in the uncastrated subject, and finally takes up an abdominal form. The gland is cranially connected to the bladder neck and caudally with the urethra, dorsally to the rectum and ventrally to the pelvic symphysis or abdominal cavity.

\section{Vascularization and Innervation}

The prostate gland is connected with the urogenital artery emanating from the internal iliac artery. In the middle of the dorsolateral surface of each prostatic lobe, the urogenital artery is diverted into a prostatic artery and a urethral prostatic artery. The internal asthmatic artery and the urethral prostatic artery anastomose to form capsular arteries which penetrate the prostatic capsule in the dorsolateral face. The prostate is drained by the iliac lymph nodes. ${ }^{2}$

Orthosympathetic innervation is provided by the hypogastric nerve originating from the caudal mesenteric ganglion and is responsible for the contraction of the gland and ejection of the prostatic fluid during ejaculation. The parasympathetic innervation is provided by the shameful nerve and the pelvic nerve, ${ }^{2,4}$ which is the origin of the second and third sacral vertebrae, and is the source of secretion of the prostatic fluid.

\section{Role of the Prostate}

The functional role of prostate in dogs is associated with the production of a liquid rich in zinc, citrate and magnesium, serving as the transport medium and facilitating sperm storage. The prostatic liquid of basic $\mathrm{pH}$ compensates for the acidity of the vaginal secretions. The volume of prostatic secretions accounts for $97 \%$ of the ejaculate volume. ${ }^{5,6}$ During the protrusion of the penis, the prostate also has a mechanical role; it closes the urethra and prevents retrograde (bladder) ejaculation through a sphincter. The latter reinforces the bladder sphincter, preventing the passage of urine. ${ }^{7,8}$

\section{PROSTATE DISORDERS IN DOGS}

\section{Benign Prostatic Hyperplasia (BPH)}

Etiology: During the dog's life, the prostate undergoes three stages of development; the first being a phase of growth from puberty to the age of 2 years. After 6 years, almost all breeds of dogs are affected by benign prostatic hyperplasia, and at the age of 9 years, $95 \%$ of the dogs with benign prostatic hyperplasia do not clinically express the symptoms of prostatic syndrome. . $^{913}$ $\mathrm{BPH}$ is associated with proliferation and increased cell volume of prostate tissue. The dog is the only animal species known to have developed this condition. ${ }^{14}$ The clinical manifestation of hyperplasia is hormone-dependent, ${ }^{9,10}$ characterized by an imbalance between the testosterone-dihydrotestosterone (DHT) ratio, a decrease in the testosterone concentration and an increase in DHT levels. The $3 \alpha$ and $3 \beta$ androstenediol, the two metabolites produced by the degradation of hydrotestosterone, are responsible for the proliferation and hypertrophy of the glandular epithelium of the prostate..$^{5,12,15}$

Clinical signs: In human medicine, the most frequently observed symptom in prostatic hyperplasia is pollakiuria, probably related to the proliferation of cellular plaques around the urethra. ${ }^{14}$

Prostate hyperplasia in dogs begins at the age of 2 years, characterized by symmetric and asymptomatic hypertrophy, non-painful, and of normal consistency. ${ }^{16}$ In medical cases, urethral discharge, hematuria, rectal tenesmus and constipation can also be observed on account of the dorsal displacement of the colon against the sacral vertebrae, rarely leading to perineal hernias following expulsive efforts. ${ }^{9,10,11,14}$ Increasing the size of the prostate is responsible for causing edema of the hindlimbs with a steep and balanced gait. In benign prostatic hyperplasia, symptoms affecting the urinary system are observed in $2.7 \%$ of the cases, while digestive symptoms account for $9.2 \%$ of the cases. ${ }^{17}$

According to a study conducted by Read, ${ }^{18}$ umbilical urethral discharge may be the only clinical symptom of benign prostatic hyperplasia in dogs. Hypofertility and hemospermia may occur with no general clinical symptoms. ${ }^{10,11,14}$ Rectal examination indicates a prostate of normal consistency, symmetrical not painful with a discrete or moderate prostatomegaly. ${ }^{11,14}$

Diagnostic approach: Clinical signs of prostatic diseases may be specific and often identical irrespective of the nature of the lesion (BPH, abscess, prostatitis, neoplasm) in relation to inflammation and prostatomegaly. Additional examinations are essential for a better clinical diagnosis:

- Prostatic washing, cytological analysis and cultivation of prostatic fluid: The cytological evaluation makes it possible to exclude an inflammatory process experienced in benign prostatic hyperplasia, where the culture tests negative, however yields a positive report in case of prostatitis.

- Radiography: The radiological examination of the caudal region of the abdomen allows for a clinical evaluation of the size and position of the prostate.

- Ultrasound: Ultrasound examination has become a tool of choice in the diagnosis of prostatic disorders in dogs. Ultrasound examination in prostate hyperplasia enables the visualization of an observable increase in the prostate volume show- 
ing modified echogenicity, marked by hyperechoic points at the beginning of prostate development and appears symmetrical with a regular capsule.

- Prostate biopsy: A histological and ultrasound examination is performed on the anesthetized animal. This procedures ensures a reliable clinical diagnosis of benign prostatic hyperplasia but is rarely practiced in veterinary medicine.

\section{Treatment Strategies}

\section{Medical treatment:}

- Estrogen: The side effects of using estrogens (oestradiolcyponate and diethylstilbestrol), which are largely used for treating squamous metaplasia and medullary aplasia, have led to the discontinuation of the use of these molecules.

- Progestogens: Progestogens (megestrol acetate, hydroxyprogesterone, medroxyprogesterone acetate and delmadinone acetate) exert an inhibitory effect on the secretion of gonadotropins and blocks the specific androgen receptors in the target organs.

Progestogens also result in a decline in the level of circulating testosterone, consequently leading to an atrophy of the gland and thus, an improvement in the related clinical symptoms. Several progestogens are used in the treatment of benign prostatic hyperplasia in dogs.

Currently in veterinary practice, the most commonly used veterinary drugs are: delmadinone acetate $\left(\right.$ Tardak $^{\circledR}, 1-2$ $\mathrm{mg} / \mathrm{kg}$ ) which is used subcutaneously at a dose of $1-2 \mathrm{mg} / \mathrm{kg}$ twice a month, osteone acetate (Ypozane ${ }^{\circledR}, 0.25-0.5 \mathrm{mg} / \mathrm{kg}$ ) is administered as an oral perfusion for 7 days, renewable per cure every 6 months and, cyproterone acetate $\left(\right.$ Androcur $^{\circledR}, 1.25-2.5$ $\mathrm{mg} / \mathrm{kg} /$ day) is administered orally for seven days.

Kawakami ${ }^{19}$ reported that progestogens can lead to oligospermia resulting in the production of abnormal spermatozoa and consequently leading to hypofertility in dogs.

Bamberg and Linde-Forsberg ${ }^{20}$ observed that no alterations of the spermogram occurred following the medical diagnosis. After conducting studies using metroxyprogestagen acetate, and megestrol acetate, no effect of progestogens were observed on the clinical parameters of the spermogram and also on the release and synthesis of hormones, gonadotropins and testosterone.

Inhibitors of $\mathbf{5 \alpha - r e d u c t a s e : ~} 5 \alpha$-reductase is necessary for the development of the prostate, and the use of the inhibitors of this enzyme is of therapeutic interest for the treatment of prostate hyperplasia. Finasteride (PROSCAR ${ }^{\circledR}$ ) is the first inhibitor of the $5 \alpha$-reductase enzyme to be commercially marketed, devoid of any estrogenic, progestational or androgenic activity. Finasteride has the advantage of not being antagonistic to the action of testosterone thus, preserving fertility in dogs.

Existing studies have demonstrated that the administration of finasteride at a dose of $1 \mathrm{mg} / \mathrm{kg} /$ day for 21 weeks could result in reversible atrophy of the prostate with protrusions and no significant difference between the treated and control groups.

Surgical treatment: Castration is the treatment of choice for benign prostatic hyperplasia. Sterilization results in a rapid and irreversible decrease in the prostate volume.

\section{Acute and Chronic Prostatitis}

Prostatitis is an inflammation of the prostate. It is generally observed in whole dogs, characterized by an increased volume and vascularization of the prostate and alterations of the glandular tissue..$^{1,17}$

Etiology: Benign prostatic hyperplasia is a favored factor, characterized by stromal alterations in the gland responsible for the sensitivity of the prostate to infections. ${ }^{11}$

In a study by Krawiec and Helfin, ${ }^{16}$ prostatic infections of bacterial origin were observed in $18 \%$ of the reported cases. In the same study, among the 33 dogs with prostatitis, 29 dogs had chronic prostatitis, and 4 dogs had prostatic abscesses.

In a study undertaken by Teske et $\mathrm{al}^{21}$ the prevalence of prostatitis was $19.3 \%$ for dogs showing prostate conditions.

Prostatitis is often observed in uncastrated dogs, but it can also occur in castrated dogs secondary to prostatic neoplasm or prostatitis prior to castration. ${ }^{11,14}$

Prostatic conditions in dogs are often ascending, of urethral origin, and rarely due to bacterial contamination of the bladder, renal or testicular origin. ${ }^{10,16,22}$

The germs are often similar to those responsible for urinary tract disorders such as Escherichia coli, but prostatitis can also be caused by several bacteria: Staphylococcus sp., Streptococcus sp., Proteus sp., Pseudomonas sp. and Klebsiella sp., Enterobacter sp., and Brucella canis. The latter often causes orchitis and epididymitis in dogs. ${ }^{10,12}$

Clinical signs: In a study by Krawiec and Helfin, ${ }^{16}$ the most common symptoms observed in prostatitis of bacterial origin were hematuria, lethargy and infertility. In the same study, $45 \%$ of the dogs with prostatitis indicated digestive problems, 33\% showed gastrointestinal signs, $30 \%$ showed systemic signs, and $18 \%$ showed locomotory symptoms.

\section{A) Acute prostatitis}

In acute prostatitis, symptoms include systemic characteristics such as fever, depression, anorexia, weakness, depression, weight loss, gastrointestinal signs (constipation, rectal tenes- 
mus) and locomotory problems (arched back, stiffness of the hind legs, a balanced gait); a purulent discharge and blood flow at the end of the penis are often frequently observed. Transrectal examination of the prostate performed for its medical diagnosis is a very painful procedure..$^{9,11,14}$

\section{B) Chronic prostatitis}

Symptoms in chronic prostatitis are subclinical. ${ }^{11}$ Dogs with chronic prostate infection have symptoms of decreased seed quality with increased forms of abnormal spermatozoa, hematospermia and hypofertility. ${ }^{11,23-25}$

Root-Kusritz and colleagues report that dogs with chronic prostatitis have chronic urinary tract infections. In uncastrated dogs with chronic urinary tract infections, chronic prostate involvement has been sought. ${ }^{14}$

Transrectal examination of the prostate is not painful, symmetrical and of a relatively hard consistency.

Diagnostic procedures: The clinical diagnosis of prostatitis in dogs requires a good anamnesis. Further examination is also necessary to establish the diagnosis:

- Red Blood Count (NFS): In acute prostatitis, neutrophilic leucocytosis is observed. ${ }^{23}$

- Cytology of the prostatic phase: The cytology of the third fraction makes it possible to demonstrate neutrophilic polynuclear cells and bacteria corresponding possibly to a prostatic infection.

- Bacteriology of prostatic lavage: When the culture tests yield negative results, prostate infection is excluded in $90 \%$ of the cases. ${ }^{25}$ Johnston $^{24}$ reported a correlation between the bacteria isolated from the bacteriological culture of prostatic massage fluid and the bacteria observed following prostate biopsy in $80 \%$ of the cases.

- Bacteriology on uroculture: When the uroculture tests are negative for prostatic infection, it is excluded in $80 \%$ of the reported cases; however, when the uroculture shows a positive result, prostatitis can be confirmed in $90 \%$ of the cases. ${ }^{26}$

- Ultrasound examination: Is an examination of choice in the case of prostatic infections in dogs. It is possible to demonstrate an increase in the prostatic volume with the modifications of the echogenicity of the prostatic parenchyma in relation to the foci of haemorrhage and necrosis. ${ }^{27}$ The hypertrophy of the iliac ganglia is not always specific to prostate conditions. ${ }^{28}$

Treatment approaches: In the case of acute prostatitis, the blood-prostatic barrier is altered, allowing for the passage of most antibiotics. The antibiotics of choice are fluoroquinolones and sulphamides-trimethoprine (S-TMP).

On the other hand, in the case of chronic prostatitis, the blood-brain barrier is unaffected, which does not allow for the diffusion of antibiotics, in which case it is necessary to use liposoluble antibiotics. Treatment should be implemented for a minimum duration of six weeks or even longer.

\section{Prostatic Cysts}

Cysts are thin-walled cavity lesions with non-purulent fluid content, localized in the prostatic parenchyma or externally located. ${ }^{14,24}$

Etiology: The etiology of prostatic cysts in most cases associated with benign prostatic hyperplasia is characterized by an increase in the prostatic secretions that exert a greater pressure on the excretory ducts. There are retention cysts as a consequence of secondary excretory duct obstruction on account of squamous prostatic metaplasia, following prolonged estrogen impregnation in testicular tumors in dogs (Table 1). ${ }^{10,12,14,23,24}$ A retrospective study showed that the cysts are the second most common form of prostatic infection encountered at a rate of $15.3 \% .^{16}$

Symptoms: Most commonly, prostatic cysts are asymptomatic, except when the size of the cysts significantly increases the prostatic volume, in which case the clinical expression and the complete prostate pathology is affected. The clinical symptoms most commonly encountered in dogs with cystic prostate lesions are rectal tenesmus, lethargy and anorexia.

According to Krawiec et al, ${ }^{16} 48 \%$ of the dogs show systemic clinical signs, 37\% show gastrointestinal symptoms, and $25 \%$ show symptoms associated with the lower urinary tract.

Diagnostic approaches: Clinical signs for prostatic cysts are varied and non-specific. Transrectal examination of the prostate during the clinical consultation makes it possible to demonstrate an asymmetry of the gland and to palpate one or more fluctuating zones. The following complementary examinations allow for an accurate clinical diagnosis.

- Radiology: Radiographic examination of the pelvic region is of little importance in diagnosis except in the case of cysts of large size, characterized by an increase in prostatic volume. ${ }^{25}$

- Urethrography: It is a technique associated with interventional radiology, which allows for the visualization of the integrity of the urethra and if possible the passage of the contrast product in the prostate, in case of an observable communication between the latter and the cysts. ${ }^{29-31}$

- Ultrasound: Ultrasound scanning of the prostate can reveal the presence of one or more variable anechoic or hypoechoic cavities of variable size, delimited by a thin wall with posterior 


\section{reinforcement. ${ }^{32}$}

Treatment: The mode of treatment depends on the size of the cyst (s).

A cyst size less than $1 \mathrm{~cm}$ is characterized by clinical symptoms demanding prostate treatment involving medical or surgical castration.

On the other hand, for a cyst with a size between 1 and $5 \mathrm{~cm}$, drainage by cytoponction under ultrasound control is performed and a sclerosing product is injected into the cavities (tetracycline, ethanol). A surgery is recommended if the cyst recurs after three cytoponctions carried out at an interval of eight days. ${ }^{25}$

\section{Prostatic Abscess}

Prostatic abscesses are purulent discharges in the parenchyma and are often caused due to a medical complication as acute prostatitis.

Etiology: Abscesses formation is often secondary to prostatitis associated with prostatic pathology (prostatic hyperplasia, squamous metaplasia, tumors).

The germs most commonly isolated from prostatic abscesses are the same as those observed during urinary infections and prostatitis, namely Escherichia coli, Proteus sp., Pseudomonas sp., Staphylococcus $s p .^{8,17}$

Clinical signs: The clinical signs observed during prostatitis in dogs are often not specific; general symptoms (depressed sensorium, anorexia, lethargy), gastrointestinal symptoms (vomiting, rectal tenesmus, constipation), and locomotory effects (balanced and stiff gait, abnormal posture at bedtime are more common on account of prostatic abscess formation. ${ }^{9,16}$

Diagnostic approaches: Transabdominal ultrasound scanning facilitates the visualization of cavities with more or less thick walls, with hypoechoic content. These parameters are often identical to that of prostatic cysts. Puncture under ultrasound control allows for differential diagnosis.

Treatment: Small abscesses, associated with medical castration, can be treated with antibiotics. However, in cases concerning bulky abscesses, antibiotic therapy alone is not enough, ${ }^{24}$ in which case it is necessary to opt for the surgical drainage of the abscesses.

Several drainage techniques are recommended: mechanical or suction drainage by penrose drains, physiological drainage by omentalization of the prostatic cavities as well as anatomical (marsupialization) drainage can be performed in dogs suffering from cavitary-type prostatic lesions. ${ }^{33-36}$
Prostate tumors are rare, presenting $5-7 \%$ of the prostatic conditions in dogs. ${ }^{37}$

Prostatic tumor processes correspond to an anarchic multiplication of the prostatic tissue, the cells most affected by this uncontrollable cell division being the epithelial cells.

In contrast to the prostatic conditions in dogs, neoplasms of the prostate involve castrated and uncastrated dogs. ${ }^{9}, 11,14,38$

Bell and colleagues ${ }^{39}$ report in a study that the prevalence of prostatic tumors in the castrated dog varies between $32 \%$ and $44.2 \%$. Adenocarcinomas are the neoplasms most commonly observed in dogs. Other neoplasias are rare: transient cell carcinoma that affects the bladder extends to the prostate, hemangiosarcoma, and lymphoma metastasis. Krawiec and Helfin ${ }^{16}$ reported in a retrospective study that the prevalence of prostatic tumors is $7.3 \%$ of the prostate disease in dogs with an average age of 10 years at diagnosis.

\section{Pathogenesis}

Prostatic tumors are always malignant. Prostate neoplasia are the most frequently encountered; however, the less observed forms of neoplasia include transitional cell carcinomas, undifferentiated carcinomas and sarcomas (leiomyosarcomas, haemangiosarcomas).

Recent studies show that castrated dogs are most commonly affected by prostate adenocarcinomas. ${ }^{21}$

Teske $^{21}$ reported that $25 \%$ of the dogs affected by prostate carcinomas are Bouviers des flondres.

\section{Symptoms}

Dogs affected by prostatic tumors show urinary symptoms (dysuria, hematuria), abdominal pain, stiff and balanced gait, with systemic signs (lethargy, weight loss, anorexia).

Transrectal examination of the prostate reveals an increase in the prostatic volume marked by an asymmetry of the lobes.

Additional tests: Cytological evaluation of the prostatic fraction of the ejaculate, prostatic lavage and cytopunction under ultrasound control makes it possible to establish the diagnosis for prostate tumors. Echo-guided transabdominal biopsy is recommended for accurate diagnosis.

Ultrasound examination of the prostate reveals a prostatomegaly with an often irregular contour, with focal zones of modified echogenicity. ${ }^{27,40}$ Cavity lesions (cysts, haemorrhage, necrosis) can also be associated with prostatic conditions. The ultrasound image of prostatic tumors in dogs is unlike that observed in humans. ${ }^{40}$ 
Prostate tumors metastasize rapidly. According to Bell's ${ }^{39}$ study based on the experimental findings by autopsy, $89 \%$ of the prostatic tumors that achieved prostatic neoplasia showed metastasis. Prostatic tumors lead to bone metastases (vertebrae, basin, femur, ovaries, scapula), visceral metastases (liver, mesentery, spleen, heart, kidney) and pulmonary metastases.

\section{Treatment}

After the completion of the local and remote extension balances by performing radiological examinations of the pelvic and abdominal region and an ultrasound scan of the abdominal region, the choice of oncological treatment is determined.

- Chemotherapy: The main clinical indication of chemotherapy is to prevent metastasis and reduce the occurrence of related medical symptoms. Recently, Hedlund ${ }^{36}$ reported that treatment with piroxicam and carprofen helps improve the survival of dogs with prostate carcinomas. The implementation of chemotherapy in a dog with neoplasia generally takes place on account of two possible situations; the first focusing on supporting the survival of the dog and, the second being associated with the toxicity and the cost of treatment. ${ }^{41}$

- Surgery: Surgical treatment involves partial or total prostatectomy. The prognosis is reserved in case of pulmonary or visceral metastasis. Radical prostate surgery is often associated with postoperative complications (urinary incontinence, strangury).

Squamous metaplasia: Squamous metaplasia is secondary to endogenous or exogenous estrogenic impregnation. It constitutes an aspect of the feminization of the male dog supported by the endogenous production of estrogens by the testicular cancer cells.

Squamous metaplasia is mainly associated with urinary and digestive symptoms (hematuria, dysuria, rectal tenesmus, constipation).

Other clinical signs that are related to feminization are distinguished on the basis of:

- Skin related symptoms: Non-pruritic alopecia that affects the genital area, the abdomen and the thorax.

- Ptosis and dermatosis of the sheath, gynecomastia, muscle slit of the forearm.

- Reduced libido, with hypofertility (Oligo-Asteno-Teratospermia), and attraction of males. ${ }^{25}$

Diagnostic approaches: The clinical signs of feminization of the male dog are evocative. Clinical diagnosis is based on the examination of the third prostatic fraction and the observation of ke- ratinized prostate cells in relation to estrogenic impregnation. ${ }^{25}$

Treatment: The treatment strategy is to perform surgical castration after having performed an assessment of extension.

Prostatic stone: The stones associated with the prostatic parenchyma are rare, and are usually observed in a routine clinical examination. ${ }^{14}$

\section{CONCLUSION}

Prostatic disorders in dogs present a uniformity in the medical symptoms affecting urinary, digestive and locomotory functions with a heterogeneity in the nature of lesions as observed in hyperplasia, prostatitis, tumor, which requires a rigorous differential diagnosis for establishing an effective medical or surgical treatment.

\section{CONFLICTS OF INTEREST}

The authors declare that there are no conflicts of interest.

\section{REFERENCES}

1. Cot S, Fontbonne A. Pathologie de la prostate chez le chien.

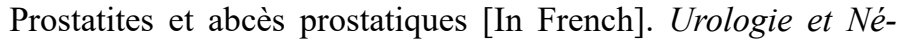
phrologie. 2001; 32: 122-125.

2. Barone R. Appareil génital mâle. In: Barone R, ed. Anatomie comparée des mammifères domestiques [In French]. Paris, France: Vigot; 1978; 3: 246-255, 181-185.

3. Evans HE, Christensen GC. The urogenital system - Male genital organs. In: Evans HE, ed. Miller's Anatomy of the Dog. Philadelphia, PA, USA: WB Saunders Company; 1993; 504-531.

4. Barsanti JA, Finco DE. Evaluation of techniques for diagnosis of canine prostatic diseases. J Am Vet Med Assoc. 1984; 185(2): 198-200.

5. Buff S. Pathologie prostatique chez le chien (II). Diagnostic Action vét. [In French]. Cah. clin. 1999; (1480 Cah. clin. n $\left.{ }^{\circ} 3\right)$, II-VII

6. Basinger R, Robinette RCL, Spaulding KA. Prostate. In: Slatter DH, ed. Textbook of Small Animal Surgery. Philadelphia, PA, USA: Saunders; 2003; 2: 1542-1557.

7. Nelson RW, Guillermo Couto C. Disorders of the prostate lland. In: Small Animal Internal Medecine. $3^{\text {rd }}$ ed. St Louis, MO, USA: Elsevier Science Health Science Division; 2003; 62: $927-$ 993.

8. Mimouni P, Dumon C. Pathologie de la reproduction, pathologie de la prostate. In: Vade-mecum de pathologie de la reproduction chez le chien [In French], Paris, France: Med'com; 
$2005 ; 208-213$.

9. Forrester SD, Purswell BJ. Diseases of the prostate. In: Leib MS, Monroe WE, eds. Practical Small Animal Internal Medicine. Philadelphia, PA, USA: WB Saunders Company; 1997: 367-382.

10. Basinger RR, Luther PB. Prostatic disease. In: Bojrab MJ, ed. Disease Mechanisms in Small Animal Surgery. Philadelphia, PA, USA: Lea \& Fabiger: 1993: 538-544.

11. Klausner JS, Johnston SD, Bell FW. Canine prostatic disorders. In: Bonagura JD, Kirk RW, eds. Current Veterinary Therapy XII. Small Animal Practice. Philadelphia, PA, USA: WB Saunders Company; 1995: 1103-1108.

12. Cotard JP. Le chien et sa prostate [In French]. Point Vet. 1988; 20(113): 7-14.

13. Memon MA. Common causes of male dog infertility. Theriogenology. 2007; 68(3): 322-328. doi: 10.1016/j.theriogenology.2007.04.025

14. Root-Kusritz MV, Klausner JS. Prostatic diseases. In: Ettinger SJ, Feldman EC,eds. Textbook of Veterinary Internal Medicine. Diseases of the Dog and Cat. Philadelphia, PA, USA: WB Saunders Company; 2000; 2: 1687-1698.

15. Coffey DS. Androgen action and the sex accessory tissues. In: Knobil E, Neill JB, eds. The Physiology of Reproduction. New York, USA: Raven Press; 1988; 1: 1081-1119.

16. Krawiec DR, Heflin D. Study of prostatic disease in dogs: 177 cases (1981-1986). J Am Vet Med Assoc. 1992; 200(8): 1119-1122.

17. Dupré G, Dupuy-Dauby L. Pathologie et traitements chirurgicaux des affections prostatiques du chien [In French]. Prat Med ChirAnim Cie. 1996; 31(6): 503-514.

18. Read RA, Bryden S. Urethral bleeding as a presenting sign of benign prostatic hyperplasia in the dog: A retrospective study (1979-1993). J Am Anim Hosp Assoc. 1995; 31(3): 261-267. doi: $10.5326 / 15473317-31-3-261$

19. Kawakami E, Washizu M, Hirano T, et al. Treatment of prostatic abscesses by aspiration of the purulent matter and injection of tea tree oil into the cavities in dogs. J Vet Med Sci. 2006; 68(11): $1215-1217$.

20. Bamberg-Thalen B, Linde-Forsberg C. Treatment of canine benign prostatic hyperplasia with medroxyprogesterone acetate. J Am Anim Hosp Assoc. 1993; 29: 221-226.

21. Teske E, Naan EC, van Dijk EM, Van Garderen E, Schalken
JA. Canine prostatecarcinoma: Epidemiological evidence of an increased risk in castrated dogs. Mol Cell Endocrinol. 2002; 197(1-2): 251-255. doi: 10.1016/S0303-7207(02)00261-7

22. Olson PN, Wrigley RH, Thrall MA, Husted PW. Disorders of the canine prostate gland: Pathogenesis, diagnosis, and medical therapy. Comp Cont Ed Pract Vet. 1987; 9(6): 613623.

23. Kamolpatana K, Johnston GR, Johnston SD. Determination of canine prostatic volume using transabdominal ultrasonography. Vet Radiol Ultrasound. 2000; 41(1): 73-77.

24. Johnston SD, Kamolpatana K, Root-Kustritz MV, Johnston GR. Prostatic disorders in the dog. Anim Reprod Sci. 2000; 6061: 405-415. doi: 10.1016/S0378-4320(00)00101-9

25. Fontbonne A, Levy X, Fontaine E, Gilson C. Techniques chirurgicales. In: Guide Pratique de Reproduction Clinique Canine et féline [In French]. Paris, France: Med'com; 2007: 231240.

26. Levy X, Maurey C, Fontaine E, Fontbonne A. Study of the aerobic bacterial flora in the canine prostate and its sensitivity to Marbofloxacine. In: Proceedings EVSSAR Symposium. Budapest, Hungary: Egmont Hungary; 2006; 281.

27. Keally J. The prostate gland. In: Diagnostic Radiology and Ultrasonography of the Dog and Cat. $4^{\text {th }}$ ed. Saint Louis, MO, USA: Elsevier Saunders. 2005: 149-156.

28. Chetboul V. Echographie de la prostate. In: Chetboul V, Pouchelon J, BUREAU-AMAGLIOS, Tessier-vetzel D, Blot S, Cotard J, SIMON M, Tainturrier D, eds. Examen échographique abdominal, oculaire et nerveux du chien et du chat [In French]. Paris, France: Masson; 2002: 195-207.

29. Morrow DA. Canine prostatic diseases. In: Current Therapy in Theriogenology: Diagnosis, Treatment and Prevention of Reproduction Diseases in Small and Large Animals. $2^{\text {nd }}$ ed. Philadelphia, PA, USA: WB Saunders Company; 1986: 553-560.

30. Rogers KS, Wantschek L, Lees GE. Diagnostic evaluation of the canine prostate. Comp Cont Ed Pract Vet. 1986; 8(11): 799-811.

31. Lattimer JC. The prostate gland. In: Thrall DE, ed. Textbook of Veterinary Diagnostic Radiology. Philadelphia, PA, USA: W.B. Saunders Company: 1998: 499-511.

32. Finn ST, Wrigley RH. Ultrasonography and ultrasoundguided biopsy of the canineprostate. In: Kirk RW, ed. Current Veterinary Therapy X. Small Animal Practice. Philadelphia, PA, USA: W.B. Saunders Company; 1989: 1227-1239.

33. Hosgood G. The omentum - The forgotten organ: Physiology and potential surgicalapplications in dogs and cats. Comp Cont 
Ed Pract Vet. 1990; 12(1): 45-50.

34. Dupuy-Dauby L. Dupré G, Bouvy B. Traitement chirurgical de 48 cas d'affections prostatiques chez le chien: étude rétrospective [In French]. Prat Med Chir Anim Cie. 1996; 31(6): 515-524.

35. Freitag TR, Jerram M, Walker AM, Warman CGA. Surgical management of common canine prostatic conditions. Comp Cont Ed Pract Vet. 2007; 29(11): 656-672.

36. Hedlund CS. Omental flaps. In: Fossum TW, Hedlund CS, Johnson AL. Small Animal Surgery. St Louis, MO, USA: Mosby Elsevier; 2007: 222-223.

37. Memon MA. Common causes of male dog infertility. The riogenology. 2007; 68(3): 322-328. doi: 10.1016/j.theriogenology.2007.04.025
38. Obradovitch J, Walshaw R, Goullaud E. The influence of castration on the development of prostatic carcinoma in the dog: 43 cases (1978-1985). J Vet Intern Med. 1987; 1: 183-187.

39. Bell FW, Klausner JS, Hayden DW, Feeney DA, Johnston SD. Clinical and pathologic features of prostatic adenocarcinoma in sexually intact and castrated dogs: 31 cases (1970-1987). J Am Vet Med Assoc. 199(11): 1623-1630.

40. Mannion P. Prostate. In: Diagnostic Ultrasound in Small Animal Practice. Oxford, UK: Blackwell Publishing; 2006; 136144.

41. Turrel JM. Management of prostatic neoplasia. In: Kirk RW, ed. Current Veterinary Therapy X. Small Animal Practice. Philadelphia, PA, USA: W.B. Saunders Company: 1989: 1193-1194. 